\title{
10 Eine Lohengrin-Parodie für Marionetten aus Angers (1892)
}

Verfügbare Quellen: Rezension der Presse.

\begin{tabular}{|l|l|}
\hline \multicolumn{2}{|l|}{ Lohengrin-Parodie für Marionetten (Angers) } \\
\hline Text & Darthenay (?) \\
\hline Musik & ? \\
\hline Aufführung & März 1892 \\
\hline Klassifizierung & $\begin{array}{l}\text { parodie dramatique d'opéra inté- } \\
\text { grale (?) et locale pour marionnettes } \\
\text { pour un auditoire public }\end{array}$ \\
\hline
\end{tabular}

Tabelle 18: Kurzinformationen Parodie aus Angers.

Über die vermutlich einmalige Aufführung einer Lohengrin-Parodie für Marionetten in Angers berichtet La Gazette de Château-Gontier : Journal politique, littéraire, agricole et commercial am 3. April 1892. Im Rahmen eines Festes, das die Mitglieder des Grand-Cercle ausgerichtet hatten, fand man sich am Abend des 28. März in der zu einem eleganten Saal hergerichteten Bibliothek der Stadt zusammen. Von den vielfältigen Darbietungen erwähnt das Blatt musikalische Beiträge unter der Mitwirkung eines Orchesters und würdigt die besagte Lohengrin-Parodie mit folgendem Satz: „Citons, parmi les principaux succès, une amusante parodie de Lohengrin, jouée sur un théâtre de fantoches, et les spirituelles marionnettes de M. Darthenay, dont l'aimable fantaisie a provoqué les plus vifs applaudissements“ (ebd.). Über das Stück selbst ist hieraus zwar nichts zu erfahren, aber es muss wohl ein Erfolg gewesen sein. Die Aufführung in einem eher improvisierten Kontext beweist, welche Popularität Lohengrin in der Stadt an der Maine seit den elf Aufführungen zwischen dem 21. Februar und 22. März des Vorjahres (1891) erlangt hat. ${ }^{335}$

Das Centre de documentation des musées Gadagne in Lyon verwahrt ein möglicherweise aus derselben Zeit stammendes Foto einer Puppentheateraufführung von Lohengrin des Théâtre Dupré aus Rouen. Es scheint aus dem Besitz Marcel Duprés zu stammen, aber das Portal artsdelamarionnette.eu, auf dem das Foto einsehbar ist, liefert diesbezüglich keine weiteren Informationen. ${ }^{336}$ 